\title{
RANCANG BANGUN SISTEM RESERVASI PARKIR ONLINE PADA PUSAT PERBELANJAAN DI KOTA DENPASAR BERBASIS WEB
}

\author{
Gede Iga Wilhamdika ${ }^{1}$, I Made Arsa Suyadnya ${ }^{2}$, Komang Oka Saputra $^{3}$ \\ Program Studi Teknik Elektro, Fakultas Teknik, Universitas Udayana Denpasar - Bali \\ Email : wilhamdikaiga@yahoo.co.id ${ }^{1}$, arsa.suyadnya@unud.ac.id ${ }^{2}$, okasaputra@unud.ac.id ${ }^{3}$
}

\begin{abstract}
Abstrak
Pusat perbelanjaan pada zaman sekarang menjadi tujuan berbelanja dan rekreasi masyarakat. Masalah yang sering dihadapi oleh pengelola pusat perbelanjaan adalah lahan parkir. Perkembangan teknologi informasi yang pesat saat ini dapat dimanfaatkan untuk membangun sebuah aplikasi yang digunakan untuk mempermudah pengemudi dalam mendapatkan tempat parkir. Pada penelitian ini, dikembangkan sebuah aplikasi reservasi parkir yang dapat digunakan untuk memudahkan pengunjung pusat perbelanjaan mendapatkan tempat parkir. Pengembangan aplikasi dimulai dari tahapan analisis kebutuhan sistem, pemodelan sistem, pembuatan sistem hingga pengujian sistem. Aplikasi ini dibangun dengan menggunakan bahasa pemrograman PHP dan database MySQL. Hasil dari penelitian ini adalah aplikasi sistem reservasi parkir online berbasis web responsif, dimana web responsif dapat beradaptasi dengan besar atau kecil layar smartphone yang digunakan. Aplikasi ini juga terintegrasi dengan layanan informasi geografis yang berguna untuk menampilkan lokasi parkir yang tersedia. Aplikasi ini dapat memastikan pengunjung pusat perbelanjaan mendapatkan slot parkir setelah melakukan reservasi. Pengujian yang dilakukan pada aplikasi ini dengan metode Black-Box, fungsional aplikasi telah dapat berjalan dengan baik dan berdasarkan pengujian System Usability Scale, nilai rata-rata yang diperoleh dari dua puluh orang responden sebesar 81,13 yang masuk dalam kategori Acceptable atau dapat diterima oleh pengguna.

Kata Kunci : Parkir, Pusat Perbelanjaan, Reservasi, Web.
\end{abstract}

Abstract
Shopping centers today are a shopping and recreation destination for the community. The problem that is often faced by managers of shopping centers is parking. The rapid development of information technology today can be used to build an application that is used to facilitate the driver in getting a parking space. In this study, a parking reservation application was developed which can be used to make it easier for visitors to the shopping center to get a parking space. Application development starts from the stage of system needs analysis, system modeling, system making up to system testing. This application is built using the PHP programming language and MySQL database. The results of this study are the application of responsive web-based online parking reservation system, where responsive web can adapt to the large or small smartphone screens used. This application is also integrated with geographic information services that are useful for displaying available parking locations. This application can ensure that shopping mall visitors get a parking slot after making a reservation. Tests carried out on this application with the Black-Box method, the functional application has been running well and based on the System Usability Scale test, the average value obtained from twenty respondents is 81.13 which is in the Acceptable category or can be accepted by the user.

Keywords: Parking, Reservation, Shopping Malls, Web.

\section{PENDAHULUAN}

Banyaknya kepemilikan kendaraan bermotor di kota Denpasar menyebabkan kebutuhan akan tempat parkir sangatlah tinggi, menurut Badan Pusat Statistik Provinsi Bali pada tahun 2013 kendaraan bermotor yang terdapat di kota Denpasar berjumlah 1,2 juta kendaraan [1]. Sebagian besar masyarakat lebih senang menggunakan kendaraan pribadi untuk berpergian ke tempat yang diinginkan, seperti untuk pergi berbelanja atau sekedar berekreasi ke mall atau pusat perbelanjaan. Pengguna Trans Sarbagita yang merupakan salah satu tranportasi masal di Bali memiliki pengguna yang sangat rendah dibandingkan dengan kendaraan pribadi, ini merupakan hasil penelitian yang dilakukan oleh Fisipol Universitas Udayana Bali (2013).[2]. 
Kapasitas tempat parkir untuk menampung kendaraan dari pengunjung sangatlah terbatas karena keterbatasan lahan parkir. Kesulitan yang dialami oleh pengendara dalam menemukan tempat parkir untuk kendaraannya memaksa pengendara tersebut untuk memarkirkan kendaraannya pada bahu jalan raya. Penggunaan bahu jalan sebagai tempat parkir selain mengakibatkan kemacetan, juga tidak terjaminnya keamanan untuk kendaraan yang diparkirkan pada bahu jalan.

Seiring dengan perkembangan teknologi informasi yang pesat saat ini, inovasi teknologi informasi dapat dimaanfaatkan untuk membantu atau mempermudah pengemudi dalam menemukan tempat parkir untuk memarkirkan kendaraannya. Beberapa inovasi pemanfaatan teknologi informasi untuk memecahkan masalah mengenai parkir kendaraan pada mall atau pusat perbelanjaan telah dilakukan. Penelitian [3] membangun sistem pendeteksi tempat parkir yang tersedia berdasarkan data karcis kendaraan yang masuk dan keluar. Visualisasi warna yang berbeda pada layar sebagai petunjuk tempat parkir yang masih kosong. Sedangkan pada penelitian [4], aplikasi yang dikembangkan adalah suatu model smartparking dengan sistem monitoring berbasis web. Rangkaian arduino, ethernet shield, sensor serta lampu/led sebagai perangkat yang mampu membangkitkan isyarat listrik pada sistem basis data, bahwa tempat parkir tersebut telah terisi. Selanjutnya dapat ditampilkan pada halaman web ketersediaan ruang parkir yang masih bisa digunakan.

Penelitian [5] merupakan penelitian yang memanfaatkan tampilan seven segment dalam menampilkan informasi slot parkir yang tersedia. Sebagai pendeteksi masuk dan keluar kendaraan digunkan sensor jarak infra merah, dengan metode client server yang terhubung dengan system kontroler slot parkir kosong akan ditampilkan pada halaman web.

Berdasarkan sulitnya pengendara menemukan tempat parkir untuk kendaraannya ketika mengunjungi pusat-pusat perbelanjaan, maka pada penelitian ini muncul sebuah gagasan untuk membuat sebuah aplikasi reservasi parkir online. Aplikasi ini juga terintegrasi dengan layanan informasi geografis yang berguna untuk menampilkan lokasi parkir yang tersedia, sehingga lokasi parkir lebih mudah ditemukan oleh pengunjung.

\section{KAJIAN PUSTAKA}

\subsection{Pengertian Parkir}

Parkir adalah keadaan kendaraan yang tidak bergerak yang bersifat sementara karena ditinggalkan oleh pengendaranya. Setiap pengendara kendaraan cenderung memarkirkan kendaraannya sedekat mungkin dengan lokasi tujuan pengendara tersebut. Sehingga ketika lokasi yang dikunjungi oleh masyarakat yang menggunakan kendaraan pribadi akan sangat sulit mendapatkan tempat untuk memarkirkan kendarannya, dikarenakan pada lokasi tersebut lahan untuk memarkirkan kendaraan sangatlah terbatas.[6].

\subsection{Konsep Pemrograman Aplikasi Berbasis Web}

Bahasa pemrograman merupakan bahasa yang dapat dipahami oleh komputer. Ada banyak bahasa pemrograman yang memiliki fungsi berbeda-beda, diantaranya bahasa pemrograman untuk membuat aplikasi desktop, membuat game, membuat aplikasi $w e b$, dan membuat aplikasi handphone. Dalam membangun website, ada beberapa komponen yang harus digunakan. Dalam penelitian ini, akan menggunakan 4 macam komponen yang memiliki peran sendiri-sendiri dalam membangun sebuah website. Keempat komponen tersebut, yaitu : HTML, CSS, Javascript dan PHP [7]

\subsection{Black-Box Testing}

Black-Box testing adalah pengujian yang dilakukan dengan mengamati hasil eksekusi melalui data uji dan memeriksa fungsional dari system yang telah dibangun. Metode ini digunakan untuk mengetahui apakah sistem aplikasi yang dibangun berfungsi sesuai dengan yang diharapkan. Pengujian aplikasi mempunyai beberapa level, untuk pengujian menggunakan metode BlackBox, terdapat enam level yaitu Integration, Functional, System, Acceptance, Beta, dan Regression [8].

\subsection{System Usability Scale (SUS)}

System Usability Scale merupakan teknik pengujian perangkat lunak ke pada user yang dilakukan dengan memeri sepuluh buah pernyataan berbentuk kuisioner. Lima buah item penilaian mulai dari sangat tidak setuju sampai sangat setuju. Pernyataan isi dari kuisioner System Usability Scale yang dapat dilihat pada Gambar 1 [9]. 


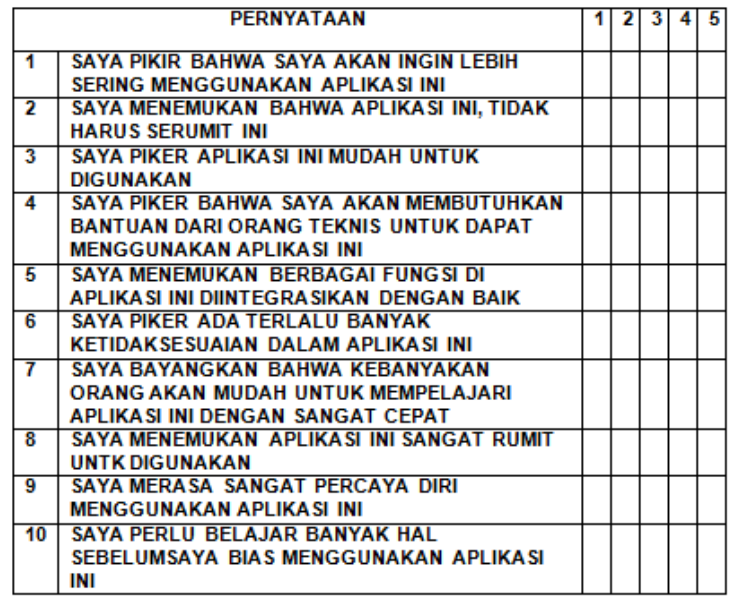

Gambar 1 Pernyataan System Usability Scale

Penggunaan kuisioner System Usability Scale dibutuhkan paling sedikitnya dua puluh orang responden. Setelah semua responden menggunakan perangkat lunak yang telah dibangun, kemudian dimnta untuk mengisi kuisioner System Usability Scale. Melakukan penghitungan nilai System Usability Scale dengan cara menjumlahkan nilai tiap pernyataan yang berkisar dari lima hingga satu. Menghitung nilai dari pernyataan dengan nomor ganjil dengan cara megurangi penilaian dari pengguna untuk nilai pernyataan tersebut dikurangi satu. Pernyataan nomor genap dihitung dengan cara nilai 5 dikurangi nilai pernyataan yang diberikan oleh responden. Setelah itu total nilai 10 pernyataan tersebut dikali dengan 2,5 sehingga mendapatkan nilai keseluruhan System Usability Scale dalam rentang 0-100. Adapun nilai rata-rata System Usability Scale yang dapat dilihat pada Gambar 2.

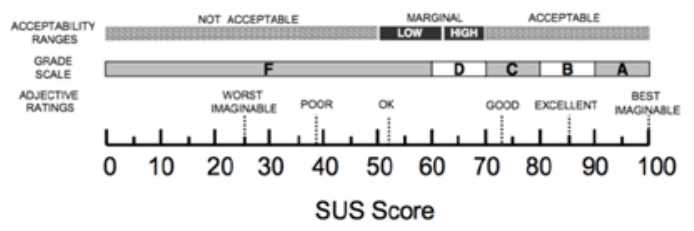

Gambar 2. Rentang Nilai Rerata SUS

\section{METODELOGI PENELITIAN}

\subsection{Tahapan Penelitian}

Tahapan penelitian yang dilakukan adalah sebagai berikut.

1. Sebagai langkah awal dilakukan identifikasi masalah pada penelitian ini, maka masalah yang ingin diteliti harus diidentifikasikan secara jelas.

2. Langkah kedua dilanjutkan dengan perumusan masalah yang ada secara rinci agar diketahui secara tepat pokok masalah dan menentukan tujuan penelitian.

3. Guna memperoleh dan lebih memahami teori-teori yang berhubungan dengan pemecahan masalah di lakukan studi pustaka.

4. Pengumpulan data dilakukan untuk memperoleh bahan penelitian sesuai dengan tujuan penelitian yang telah ditetapkan.

5. Pemodelan sistem aplikasi dari rancang bangun sistem reservasi parkir online pada pusat perbelanjaan di kota Denpasar berbasis web ini dibuat dalam bentuk Diagram Konteks, Flowchart, Data Flow Diagram (DFD) dan Entity Relationship Diagram (ERD).

6. Perancangan database yang terstruktur untuk menentukan atribut, entitas, serta relasi yang terjadi diantara masingmasing entitas.

7. Pembuatan aplikasi web, rancang bangun sistem reservasi parkir online pada pusat perbelanjaan di Kota Denpasar berbasis web.

8. Pada penelitian ini dilakukan pengujian aplikasi yang sudah jadi ke pengguna untuk mendapatkan hasil feedback dengan menggunakan metode pengujian System Usability Scale dan Black-Box.

9. Langkah terakhir adalah pengambilan kesimpulan mengenai penelitian.

\subsection{Gambaran Umum Sistem}

Member atau pelanggan yang ingin melakukan reservasi harus login terlebih dahulu, jika pelanggan belum terdaftar menjadi member dapat langsung melakukan pendaftaran pada aplikasi ini. Member atau pelanggan harus membeli saldo untuk dapat melakukan reservasi parkir dengan cara mentransfer sejumlah uang. Admin atau operator bertugas menginputkan atau memvalidasi top up yang dilakukan oleh member. Pada saat member datang untuk memarkirkan kendaraannya yang sebelumnya telah melakukan reservasi di aplikasi, operator harus meminta member menunjukan bukti reservasinya. Adapun gambaran umum sistem dapat dilihat pada Gambar 3. 


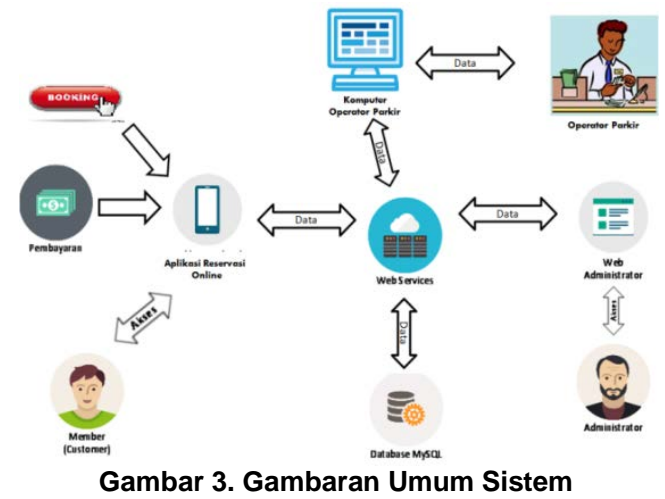

Berdasarkan Gambar 3, dapat dijelaskan langkah yang akan dilakukan dalam penggunaan aplikasi ini. Member atau pelanggan yang ingin melakukan reservasi harus login terlebih dahulu, jika pelanggan belum terdaftar menjadi member dapat langsung melakukan pendaftaran pada aplikasi ini. Member atau pelanggan harus membeli saldo untuk dapat melakukan reservasi parkir dengan cara mentransfer sejumlah uang ke rekening yang ditunjukkan pada aplikasi. Setelah member mentransfer pembayaran untuk membeli saldo, member harus menginputkan foto bukti transfer pada form yang tersedia pada aplikasi.

Reservasi tempat parkir langsung bisa dilakukan ketika telah mentransfer pada rekening yang ada pada aplikasi. Member dapat memilih lokasi parkir dan jam parkir yang diinginkan melalui aplikasi reservasi parkir ini. Admin atau operator bertugas menginputkan atau memvalidasi top up yang dilakukan oleh member. Pada saat member datang untuk memarkirkan kendaraannya yang sebelumnya telah melakukan reservasi di aplikasi, operator harus meminta member menunjukan bukti reservasinya. Ketika member ingin meninggalkan lokasi parkir, operator memberikan struk parkir kepada member tersebut sekaligus meminta kekurangan biaya parkir jika saldo dari member tersebut kurang. Setelah member meninggalkan tempat parkir, tempat parkir yang digunakan oleh member tersebut harus diubah statusnya menjadi bebas reservasi.

\subsection{Pemodelan Sistem}

Berdasarkan analisis kebutuhan sistem, maka dapat dibuat suatu pemodelan sistem yang dapat menjelaskan secara detail prosesproses dan aliran arus data yang ada pada Rancang Bangun Sistem Reservasi Parkir Online pada Pusat Perbelanjaan Berbasis Web. Dalam penelitian ini akan menggunakan pemodelan sistem dalam bentuk diagram konteks dan DFD level 0.

Diagram konteks Rancang Bangun Sistem Reservasi Parkir Online pada Pusat Perbelanjaan Berbasis Web dapat dilihat pada Gambar 4.

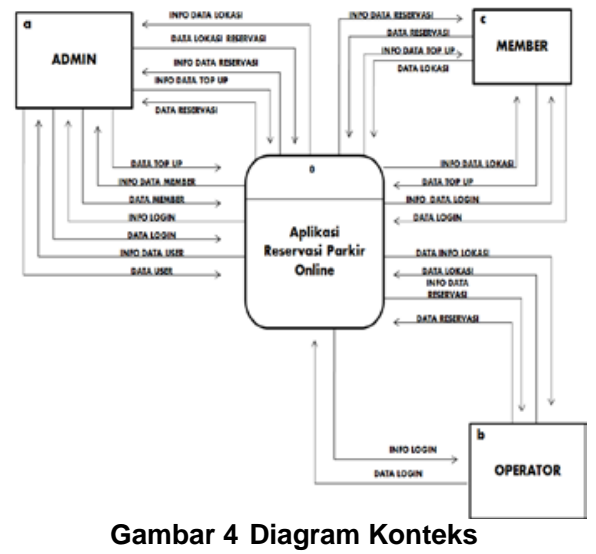

Seperti dilihat pada Gambar 4, Pada diagram konteks terdapat external entity yang melakukan kegiatan memberi data maupun yang menerima data. Ada entity utama pada diagram konteks ini yaitu administrator, member dan operator. Pada diagram konteks hanya mewakili satu proses saja, dimana satu proses itu mencakup keseluruhan sistem.

DFD Level 0 merupakan detail dari proses yang terjadi pada Rancang Bangun Sistem Reservasi Parkir Online pada Pusat Perbelanjaan Berbasis Web. Bagaimana alur proses yang terjadi, beberapa proses yang ada dan penyimpanan data yang digunakan pada aplikasi. Hal tersebut dapat dilihat pada gambar 5 .

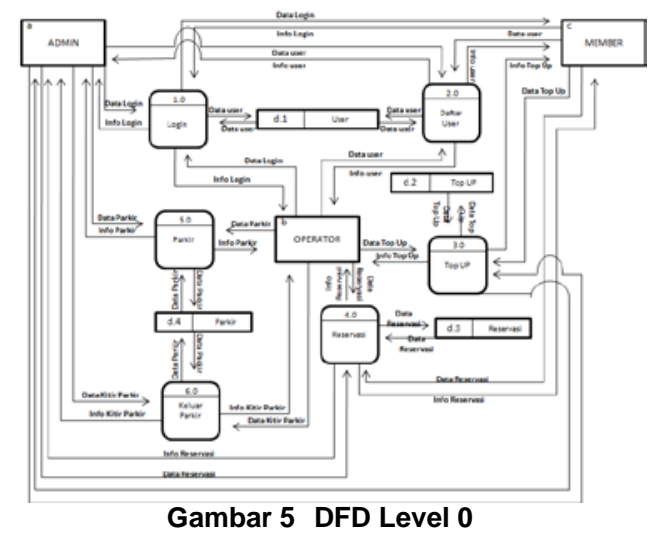

\subsection{Perancangan Database}

Perancangan Basis Data mencakup ERD (Entity Relationship Diagram) dan relasi antar tabel. ERD digunakan untuk memodelkan struktur data dan hubungan antar data, Entity Relationship Diagram dapat dilihat pada Gambar 6. 


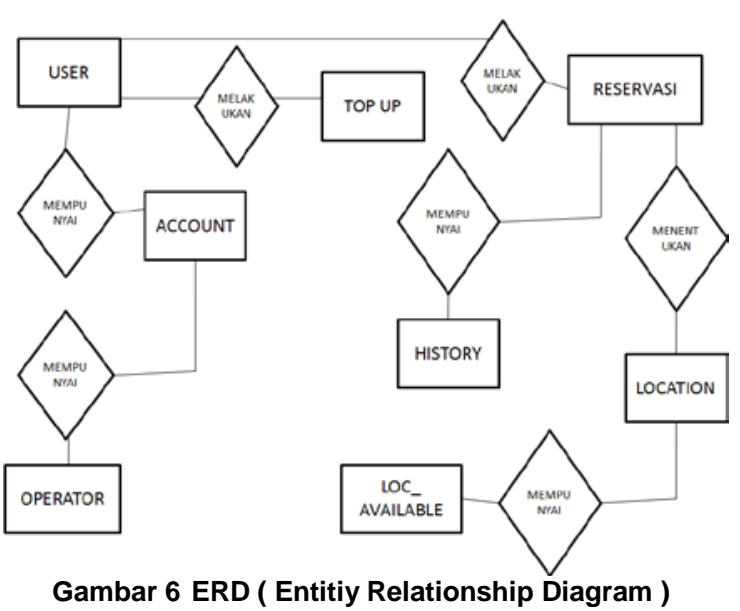

Gambar 6 menunjukan bahwa, pada entitas user memiliki atribut-atribut seperti Id, email, name, address, phone, dan balance. Pada entitas account memiliki atribut-atribut seperti id, email, password, dan role. Pada entitas operator memiliki atribut-atribut seperti id, name, email, dan location. Pada entitas reservasi memiliki atribut - atribut seperti id, police_number, color, res_at, expiry_at, in_at, user_id, location_id, dan status. Pada entitas history memiliki atribut - atribut seperti id, id_reservasi, check_out, cost, dan operator. Pada entitas location memiliki atribut - atribut seperti id, name, capacity, address, latitude, longitude, phone, dan email. Pada entitas loc_available memiliki atribut - atribut seperti id, location_id, available. Pada entitas top_up memiliki atribut - atribut seperti id, date, member_name, balance, resi, photo dan status.

Relasi antar tabel merupakan hubungan antar satu tabel dengan tabel lainnya di data base. Relasi antar tabel dapat dilihat pada Gambar 7.

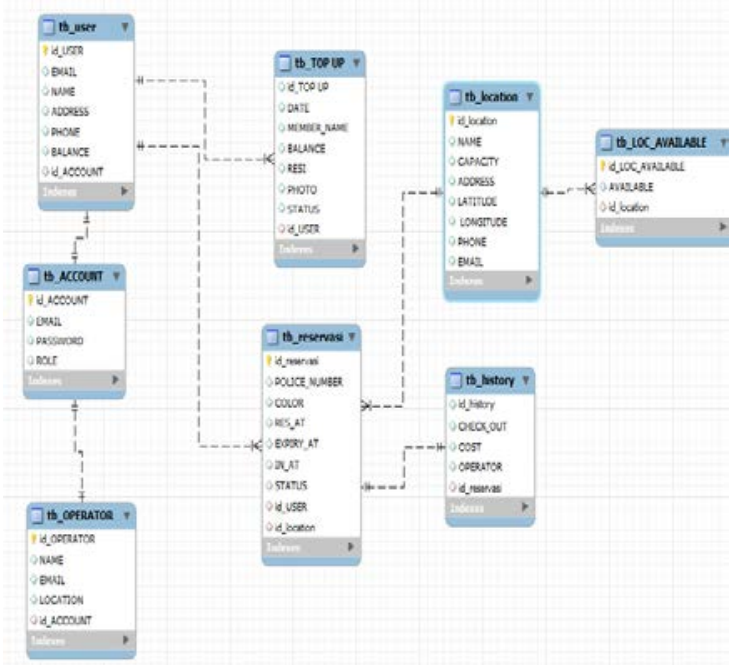

Gambar 7 Relasi Antar Tabel

\section{HASIL DAN PEMBAHASAN}

\subsection{Hasil}

Sistem reservasi parkir online yang dibangun dapat menangani proses reservasi parkir secara online, agar memudahkan pengguna mendapatkan slot parkir untuk kendaraannya. Aplikasi ini juga terintegrasi dengan google maps yang akan memudahkan pengguna menemukan lokasi parkir. Pada aplikasi ini pengguna juga dimudahkan dalam pembayaran parkir, dimana pengguna terlebih dahulu mengisi saldo dengan cara mentransferkan sejumlah uang. Dengan demikian pengguna tidak lagi menggunakan uang tunai dalam pembayaran parkir. Aplikasi ini berbasis web responsif yang akan dapat beradaptasi dengan besar atau kecil layar smartphone yang digunakan oleh pengguana. Pada aplikasi ini pengguna harus memiliki akun agar dapat menggunakan sistem reservasi parkir online ini, setelah itu pengguna harus mengisi saldo agar dapat melakukan reservasi pada lokasi yang telah tersedia pada aplikasi ini.

\subsubsection{Halaman Login}

Tampilan halaman login, Gambar 8 merupakan halaman pertama yang akan dilihat oleh user.

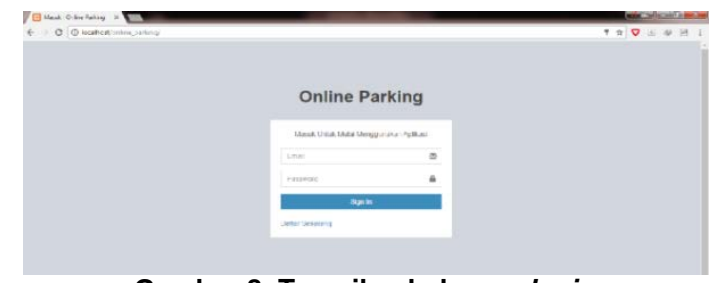

Gambar 8. Tampilan halaman login

User yang telah terdaftar dapat langsung login dengan cara memasukan email dan password yang telah terdaftar pada aplikasi ini. User yang belum terdaftar atau tidak memiliki akun pada aplikasi ini harus mendaftar terlebih dahulu dengan menekan tombol daftar sekarang.

\subsubsection{Halaman Utama Admin}

Halaman utama admin, Gambar 9 akan muncul ketika user login menjadi admin. 


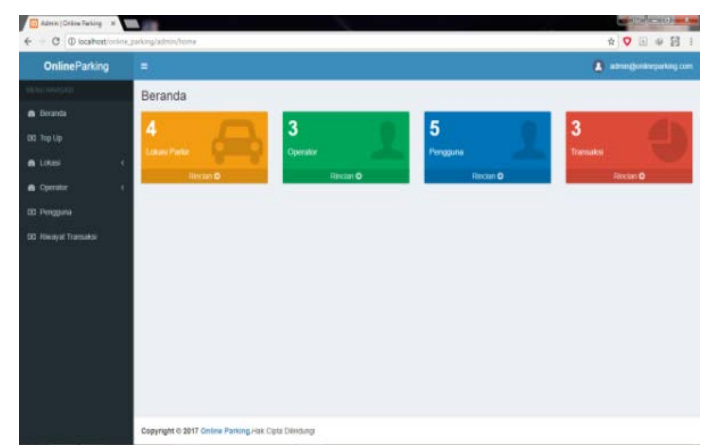

Gambar 9. Tampilan Halaman Utama Admin Pada halaman ini terdapat menu yang dapat diakses oleh admin di bagian sidebar, antara lain, menu Beranda, menu Top up, Menu Lokasi, menu Operator, menu Pengguna, dan menu Riwayat Transaksi. Pada bagian header terdapat menu Pengaturan dan Menu Keluar.

\subsubsection{Halaman Validasi Top Up}

Halaman validasi top up, Gambar 10 ini berfungsi sebagai halaman validasi top up yang dilakukan oleh admin ketika ada member yang melakukan top up.

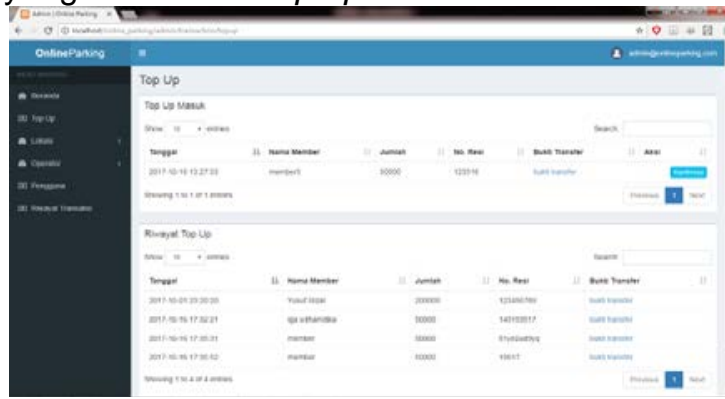

Gambar 10. Tampilan Halaman Top Up Admin

Proses yang terjadi pada halaman ini yaitu admin akan memvalidasi top up yang dilakukan oleh member. Admin harus mengecek bukti transfer yang dikirimkan oleh member dengan cara mengklik tulisan bukti transfer yang berwarna biru, setelah itu akan muncul gambar struck transfer yang dikirim oleh member. Jika data sudah benar admin harus mengklik tombol konfirmasi.

\subsubsection{Halaman Tambah Lokasi}

Halaman Tambah Lokasi ini berfungsi sebagai halaman menambahkan lokasi parkir yang akan digunakan pada aplikasi ini, halaman ini hanya bisa diakses oleh admin. Lebih jelasnya dapat dilihat pada Gambar 11.

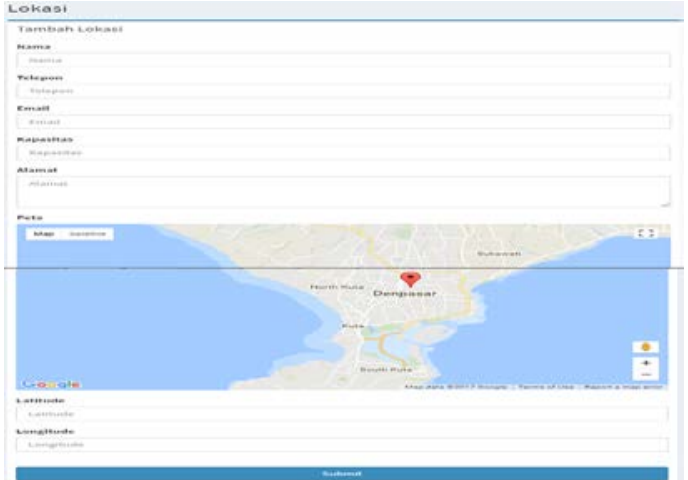

Gambar 11. Tampilan Tambah Lokasi

Ketika admin ingin menambahkan lokasi baru pada aplikasi ini, admin harus mengisi seluruh data yang diminta oleh sistem, untuk mengisi latitude dan longitude admin hanya mengeser pin yang ada pada peta yang terdapat pada form tambah lokasi ke lokasi yang diinginkan, kemudian data latitude dan longitude terisi dengan otomatis.

\subsubsection{Menu Halaman Manage Lokasi}

Halaman Manage Lokasi Parkir, Gambar 12. Tersedia berfungsi untuk mengatur semua lokasi parkir yang terdapat pada aplikasi ini. Halaman ini berisi fungsi hapus dan ubah untuk data lokasi parkir.

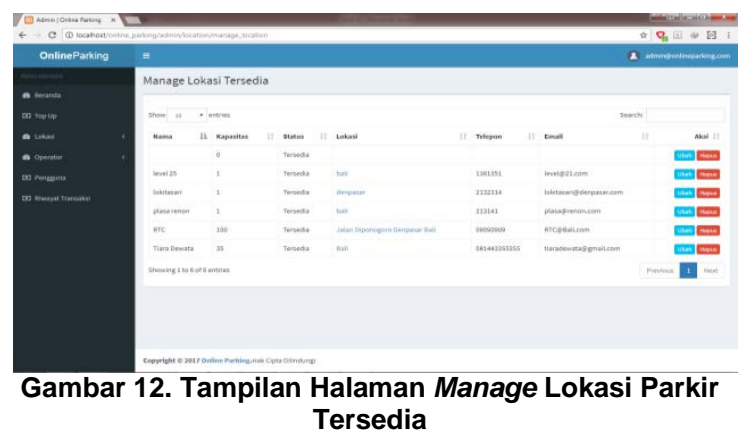

\subsubsection{Halaman Tambah Operator}

Halaman Tambah Operator, Gambar 13 berfungsi untuk menambahkan operator pada masing-masing tempat parkir yang tersedia pada aplikasi ini, halaman ini hanya bisa diakses oleh admin.

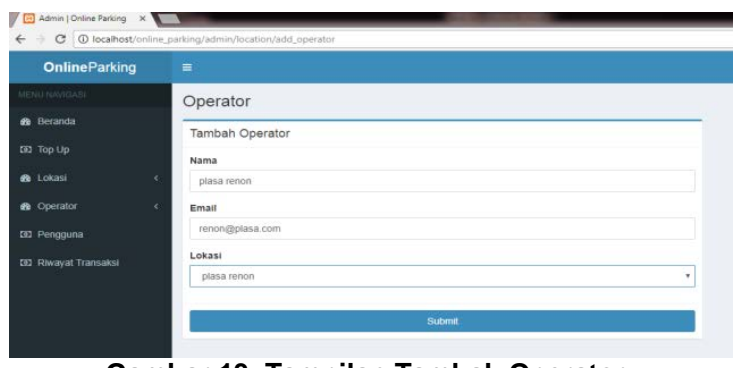

Gambar 13. Tampilan Tambah Operator 
Admin dapat menambahkan operator sesuai dengan kebutuhan yang diperlukan. Data yang diminta oleh sistem harus diisi dengan benar oleh admin.

\subsubsection{Halaman Home Operator}

Halaman Home Operator, Gambar 14 akan muncul ketika user login menjadi operator.

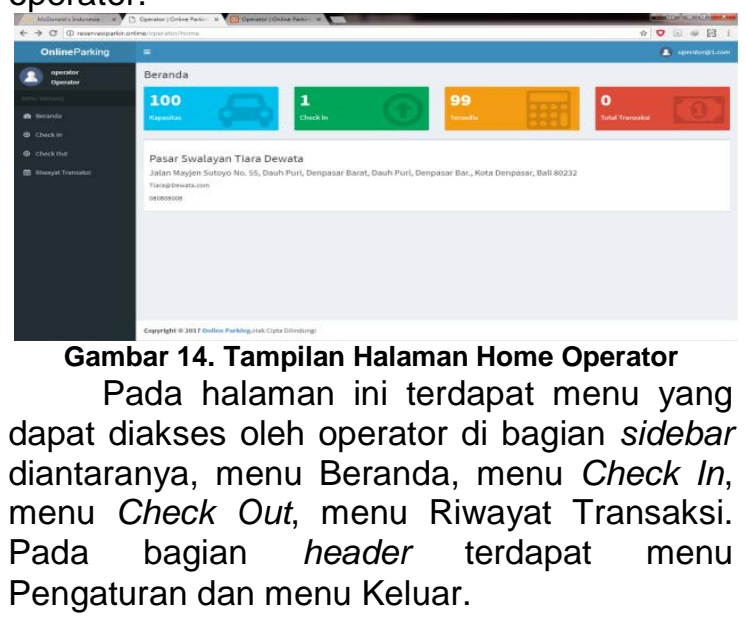

\subsubsection{Halaman Home Member}

Halaman Home Member, Gambar 15, akan muncul ketika user login menjadi member.

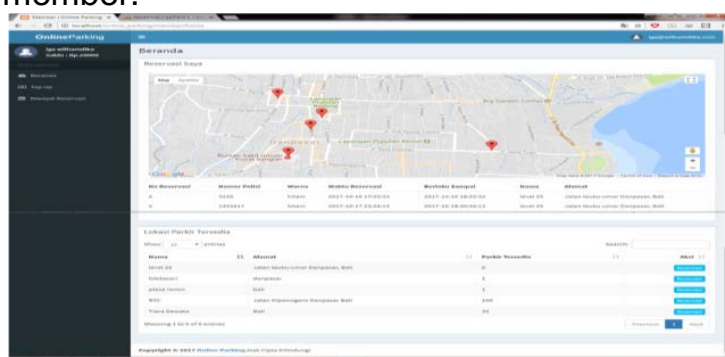

Gambar 15. Tampilan Halaman Home Member

Pada halaman ini terdapat menu yang dapat diakses oleh member di bagian sidebar, antara lain menu Beranda, menu Top Up, menu Riwayat Transaksi, dan terdapat juga informasi mengenai jumlah saldo member pada bagian pojok kiri atas. Ketika saldo member tersebut tidak cukup untuk melakukan reservasi maka akan muncul text box. Hal ini dapat dilihat pada Gambar 16.

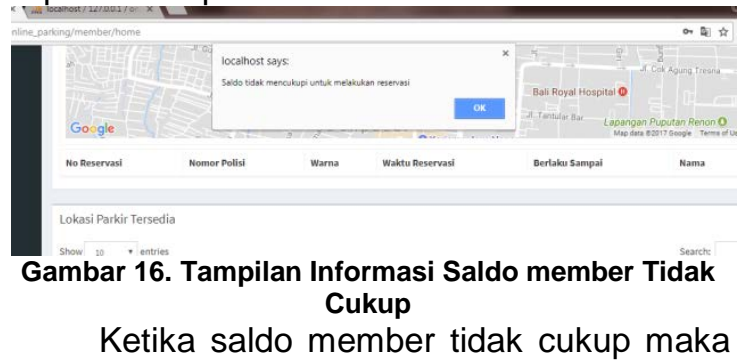
member harus melakukan top up saldo untuk bisa melakukan reservasi. Setelah member melakukan top up, dan jumlah saldo member tersebut cukup untuk melakukan reservasi maka akan muncul text box. Hal ini dapat dilihat pada Gambar 17.

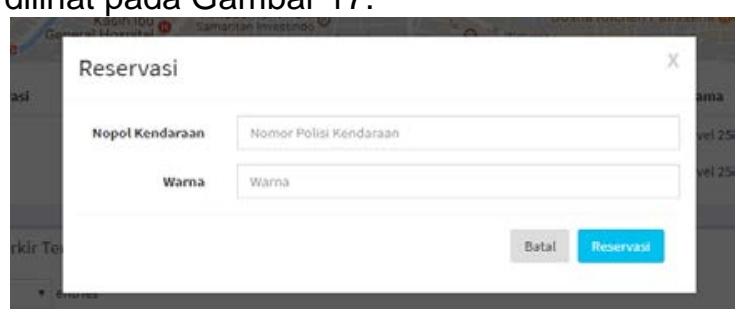

Gambar 17. Tampilan Text Box Reservasi

Setelah text box tersebut muncul, member harus mengisi data yang diminta oleh aplikasi. Setelah data terisi, tekan tombol reservasi. Apabila user menekan tombol reservasi tersebut akan muncul bukti reservasi di bawah peta, ditunjukan pada Gambar 18.

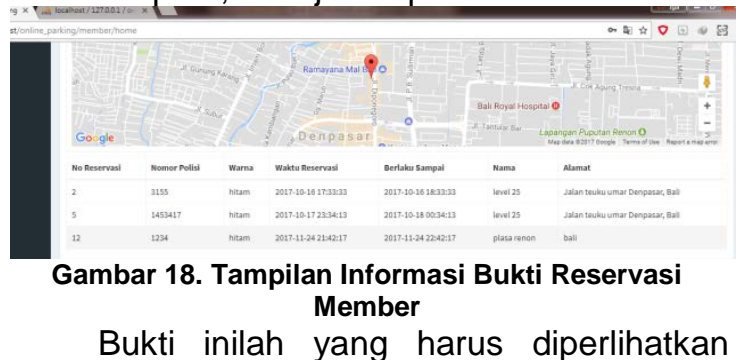
oleh member kepada operator pada saat member tersebut datang ke lokasi parkir. Pada bukti ini juga terdapat batas kadaluarsa reservasi member tersebut.

\subsubsection{Halaman Top Up}

Halaman Top Up, Gambar 19 berfungsi untuk menambah saldo member guna melakukan reservasi pada aplikasi ini.

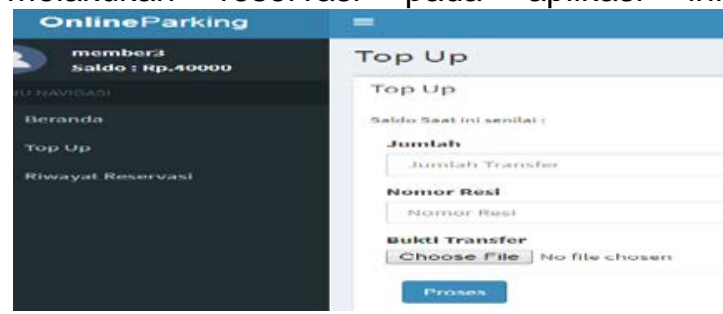

Gambar 19. Tampilan Halaman Top Up Member

Untuk menambah saldo, member harus melakukan top up dengan cara mentransferkan sejumlah uang. Bukti transfer dimasukan pada form yang terdapat pada halaman top up setelah semua data terisi member menekan tombol proses.

\subsection{Pembahasan}

Untuk mengetahui unjuk kerja sistem yang telah dibangun pada penelitian ini maka harus dilakukan pengujian sistem. Pengujian yang digunakan untuk menguji dalam aplikasi 
reservasi parkir online ini menggunakan pengujian black-box dan System Usability Scale. Sistem aplikasi yang telah dibangun diuji hanya dilihat berdasarkan keluaran yang dihasilkan dari data atau kondisi masukan yang diberikan untuk fungsi yang ada tanpa melihat bagaimana proses untuk mendapatkan keluaran tersebut dan melalui kuisioner berisi pernyataan mengenai aplikasi reservasi parkir online yang dibagikan kepada masing-masing pengguna yang telah dibagikan pada masyarakat umum dan operator parkir. User/pengguna yang dilibatkan yaitu :

1. Masyarakat umum (15 orang)

2. Operator parkir (5 orang)

Masing-masing pengguna diberikan kesempatan untuk menggunakan aplikasi reservasi parkir online yang telah dibuat dan diberikan beberapa pernyataan untuk mendapatkan nilai seberapa baik aplikasi yang sudah dibangun tersebut.

Berdasarkan hasil pengujian dengan metode black-box keseluruhan fungsional aplikasi reservasi parkir online berfungsi dengan baik. Dapat dilihat pada Tabel 1. Tabel 1. Pengujian black-box.

\begin{tabular}{|c|c|c|c|}
\hline No & NAMA PENGUILAN & JENIS PENGUULAN & HASIL PENGUILAN \\
\hline 1 & AUTENTIFIKASI LOGIN & SISTEM & BERHASIL \\
\hline 2 & REGISTRASI & SISTEM & BERHASIL \\
\hline 3 & HaLAMAN TOP UP & SISTEM & BERHASIL \\
\hline 4 & KONFIRMASI TOP UP & SISTEM & BERHASIL \\
\hline 5 & HaLaMAN TAMB AH LOKASI & SISTEM & BERHASIL \\
\hline 6 & TAMBAH LOKASI & SISTEM & BERHASIL \\
\hline 7 & HaLaMAN MaNAGE LOKASI & SISTEM & BERHASIL \\
\hline 8 & HAPUS LOKASI & SISTEM & BERHASIL \\
\hline 9 & Чван LOKASI & SISTEM & BERHASIL \\
\hline 10 & $\begin{array}{c}\text { MaLAMQN PETA LOKASI } \\
\text { TERSEDLA } \\
\end{array}$ & SISTEM & BERHASIL \\
\hline 11 & HALAMAN TAMBAH OPERATOR & SISTEM & BERHASIL \\
\hline 12 & TAMBAH OPERATOR & SISTEM & BERHASIL \\
\hline 13 & HALAMAN MANAGE OPERATOR & SISTEM & BERHASIL \\
\hline 14 & MAPUS OPERATOR & SISTEM & BERHASIL \\
\hline 15 & HALAMQN PENGGUNMa & SISTEM & BERHASIL \\
\hline 16 & $\begin{array}{l}\text { HALAMQN RINAYAT TRANSAKSI } \\
\text { ADMIN }\end{array}$ & SISTEM & BERHASIL \\
\hline 17 & BERANDA OPERATOR & SISTEM & BERHASIL \\
\hline 18 & HALAMAN CHECK IN & SISTEM & BERHASIL \\
\hline 19 & CHECK IN & SISTEM & BERHASIL \\
\hline 20 & HALAMAN CHECK OUT & SISTEM & BERHASIL \\
\hline 21 & CHECK OUT & SISTEM & BERHASIL \\
\hline 22 & $\begin{array}{l}\text { HALAMAN RINAYAT TRANSAKSI } \\
\text { OPERATOR }\end{array}$ & SISTEM & BERHASIL \\
\hline 23 & BERANDA MEMEER & SISTEM & BERHASIL \\
\hline 24 & RESERVASI & SISTEM & BERHASIL \\
\hline 25 & HALAMAN TOP UP & SISTEM & BERHASIL \\
\hline 26 & TOP UP & SISTEM & BERHASIL \\
\hline 27 & $\begin{array}{l}\text { HQLAMAN RINAYAT TRANSAKSI } \\
\text { MEMBER }\end{array}$ & SISTEM & BERHASIL \\
\hline
\end{tabular}

Dari hasil pengujian pada Tabel 1 dapat dilihat bahwa semua fungsi yang diuji dinyatakan berhasil.

Pengujian usability melalui kuisioner diberikan kepada dua puluh responden, dimana masing-masing responden diberikan sepuluh buah pernyataan. Hasil pengujian usability testing ini ditunjukan pada Tabel 2.
Tabel 2. Hasil pengujian usability

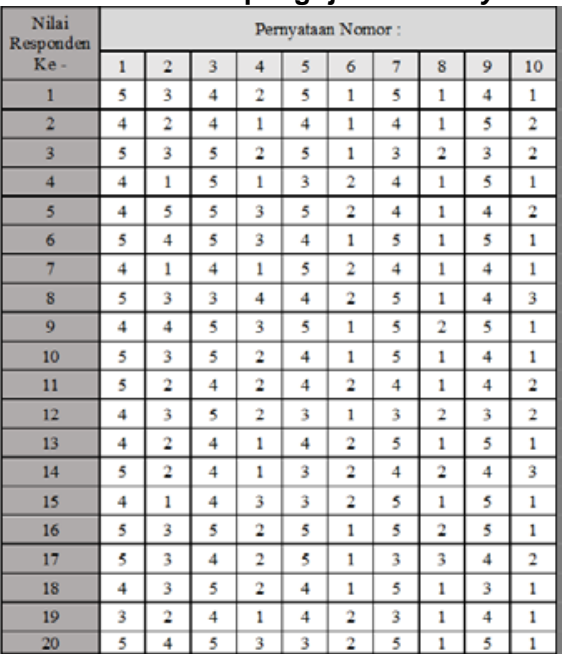

Kuisioner yang telah dibagikan kepada responden kemudian diolah datanya menggunakan system usability scales ehingga mendapatkan hasil yang dapat dilihat pada Tabel 3.

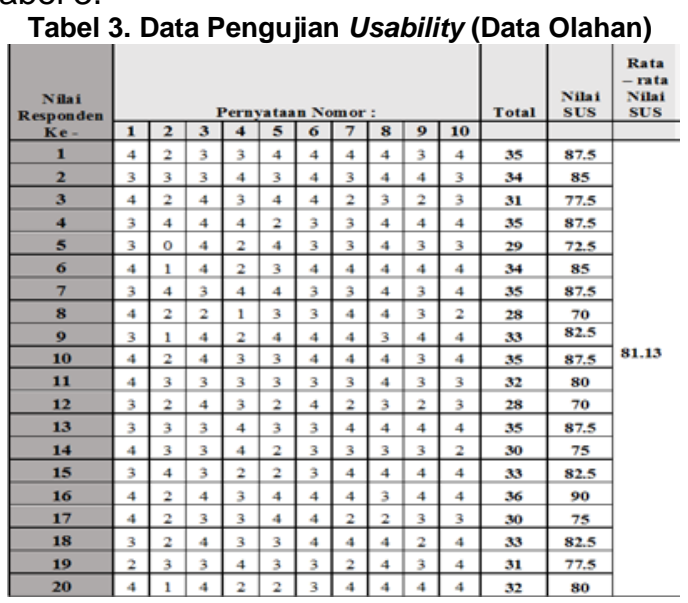

Dari Tabel 3, perangkat lunak mempunyai kualitas yang baik bila berada pada score 70 ke atas. Untuk kasus ini nilai System Usability Scale yang didapat dari rata-rata nilai yang didapat dari dua puluh responden sebesar 81,13. Hasil tersebut menunjukkan bahwa aplikasi memiliki tingkat usabilitas diatas ratarata karena berada diatas angka 70 . Berdasarkan nilai System Usability Scale tersebut, maka Aplikasi Reservasi Parkir Online Pada Pusat Perbelaanjaan di Kota Denpasar Berbasis Web berarti bernilai Grade Scale $=\mathrm{B}$, dan Adjective Rating $=$ Excellent . Jika dikonversikan menurut standar brooke (1996) masuk dalam kategori Acceptable atau dapat diterima oleh pengguna jika dikonversikan menurut kisaran Rating penerimaan. 


\section{Kesimpulan}

Rancang Bangun Sistem Reservasi Parkir Online Pada Pusat Perbelanjaan di Kota Denpasar Berbasis Web, diperoleh kesimpulan sebagai berikut :

1. Rancang Bangun Sistem Reservasi Parkir Online Pada Pusat Perbelaanjaan di Kota Denpasar Berbasis Web ini dibangun berdasarkan hasil analisis kebutuhan sistem, selanjutnya dilanjutkan pemodelan desain aplikasi menggunakan Data Flow Diagram (DFD) dan perancangan basis data berupa Entity Relationship Diagram (ERD) setelah itu pembuatan Database untuk menyimpan data hasil pengolahan sistem menggunakan DBMS MySQL, setelah itu aplikasi dibangun dengan menggunakan bahasa pemrograman HTML dan PHP.

2. Sistem reservasi parkir online ini dilengkapi dengan sistem layanan informasi geografis guna memudahkan pengguna menemukan lokasi tempat parkir yang tersedia pada aplikasi ini.

3. Sistem reservasi parkir online ini menampilkan jumlah slot parkir yang tersedia di masing-masing lokasi parkir yang ada pada sistem aplikasi ini. Pelanggan yang telah melakukan reservasi dipastikan mendapatkan slot parkir untuk kendaraannya di lokasi parkir yang telah direservasi oleh pelanggan. Seluruh data reservasi tercatat pada database.

4. Sistem aplikasi yang dibangun memiliki tampilan yang responsive atau menyesuaikan tampilan secara otomastis berdasarkan alat yang digunakan untuk mengakses system.

5. Hasil pengujian fungsionalitas aplikasi menggunakan Black-Box, semua fungsi dalam aplikasi berhasil pada saat fungsi tersebut digunakan. Berdasarkan hasil nilai rata-rata pengujian mengunakan System Usability Scale (SUS), maka dapat diartikan aplikasi yang dibangun memiliki nilai rata-rata sebesar 81,13 yang masuk dalam kategori Acceptable atau dapat diterima oleh pengguna.

\section{DAFTAR PUSTAKA}

[1] Anonim. 2013. Banyaknya Kendaraan Bermotor Menurut Jenis Kendaraan dan Kabupaten / Kota di Bali Tahun 2013.

[2] Masuki. 2013. Pengguna Trans Sarbagita di Bali Rendah.
[3] Ardiana, F. 2012. Rancang Bangun Aplikasi Visualisasi dan Administrasi Manajemen Parkir Pada Suatu Pusat Perbelanjaan. Skripsi. S1 / Jurusan Sistem Informasi, Sekolah Tinggi Manajemen Informatika dan Teknik Komputer Surabaya.

[4] Baharuddin, Palantei, Syahlan, Ahmad, Nurrahmillah, Tahir, dan Nauman. 2013. Pengembangan Sistem Perpakiran Cerdas Terintegrasi Web. Jurusan Teknik Informatika, STMIK Dipanegara, Prodi Teknik Elektro, Fakultas Teknik, Universitas Hasanuddin.

[5] Sanjaya, A.G. 2012. Prototipe Sistem Informasi Kendali Parkir Tersedia Menggunakan Tampilan Seven Segment. Jurusan Teknik Informatika Sekolah Tinggi Manajemen Informatika dan Komputer Yogyakarta.

[6] Direktorat Bina Sistem Lalu Lintas dan Angkutan Kota. 1998. Pedoman Perencanaan dan Pengoperasian Fasilitas Parkir. Jakarta: Direktorat Jenderal Perhubungan Darat.

[7] WAHANA KOMPUTER. 2010. Panduan Belajar MySQL Database Server. Jakarta: PT. TransMedia.

[8] Williams, L. 2006. Testing Overview and Black - Box Testing Techniques

[9] Brooke, John. (1996). SUS - A quick and dirty usability scale. Beaconsfield :Redhatch Consulting Ltd. 